\title{
Alfabetização e letramento no cenário escolar: compreensões de gestores educacionais
}

\author{
Otilia Lizete de Oliveira Martins Heinig*
}

\section{Resumo}

A pesquisa "A compreensão do letramento nas novas gestôes educacionais" foi realizada com gestores educacionais responsáveis pelos anos iniciais do Ensino Fundamental de seis municípios de Santa Catarina. O objetivo deste artigo é compreender a concepção de linguagem que fundamenta a implantação do Ensino Fundamental de nove anos. O instrumento de coleta de dados foi a entrevista narrativa. Dos enunciados, depreende-se que letramento e alfabetizaçáo são compreendidos dicotomicamente, o que implica o fazer pedagógico e nele o papel do professor e a organização curricular. Há também uma inquietude quanto ao ensino da leitura e da escrita no primeiro ano.

Palavras-chave: Alfabetização. Ensino de segundo grau. Leitura. Escrita.

* Doutora em Linguística pela UFSC, professora em tempo integral na FURB (Universidade Regional de Blumenau) no Programa de Pós-graduação em Educação e no curso de Letras. 


\section{Ingressando na leitura: os caminhos da pesquisa}

Ler e escrever, sob a ótica das pequenas crianças que se inserem no universo escolar, é um desafio que se apresenta, por vezes, divertido; por outras, preocupante. Entretanto, todas elas trazem consigo, seja por desejo pessoal ou pelo discurso circulante, a veleidade de ingressar no universo da palavra escrita. Esse contexto tem motivado as pesquisas que desenvolvemos nos últimos anos e que nos levaram a um espaço mais amplo, o da gestão escolar.

Este artigo é um recorte da pesquisa "A compreensão do letramento nas novas gestôes educacionais", cujo objetivo geral é depreender a concepção de alfabetização e de letramento que orienta o ensino da leitura e da escrita para o Ensino Fundamental de nove anos nas novas gestóes educacionais do Médio Vale do Itajaí, Santa Catarina. Neste artigo, partindo da compreensão da concepção de linguagem enunciada pelos gestores, pretende-se analisar as relaçóes estabelecidas entre alfabetização e letramento e as suas implicaçóes no fazer pedagógico e na organização curricular no processo de implantação do Ensino Fundamental de nove anos.

Em uma perspectiva dialógica, as respostas são provisórias e novas perguntas se apresentam, colocando o pesquisador no fio discursivo entre palavras e contrapalavras. As discussóes e reflexóes deste artigo foram provocadas pelos dados da pesquisa de Heinig e Stolf (2008), na qual os professores foram convidados a falar sobre o processo de ensino/aprendizagem da leitura e escrita nos anos iniciais do ensino de nove anos. Os resultados instigaram um outro olhar, dessa vez voltado aos gestores responsáveis pelos anos iniciais de cada município. Entre 2008-2010, desenvolvemos uma pesquisa que, a partir dos enunciados dos gestores educacionais, tinha o intuito de compreender as concepções de alfabetização e letramento que circulam nas secretarias de educação da Associação dos Municípios do Médio Vale do Itajaí (AMMVI). Para este momento, trazemos os enunciados de seis gestores que haviam participado da primeira etapa da pesquisa e renovaram as suas gestóes. Todos os municípios oferecem o Ensino Fundamental de nove anos, mas poucos desenvolveram uma proposta curricular para esse novo momento educacional.

Com os sujeitos da pesquisa, realizamos uma entrevista, a qual é, aqui, compreendida como um momento de interação verbal entre sujeitos 
socialmente organizados que produzem sentidos para os enunciados proferidos, objetivando compreensáo por parte de todos os participantes. Assim, a entrevista é delineada como responsiva, uma vez que contém, em sua natureza, o pedido por resposta, pois aquele que ouve concorda, discorda, completa, silencia repensa (BAKHTIN, 1992). Por conseguinte, compreendemos a entrevista como dialógica, pois "[...] ela estabelece uma relação de sentido entre os enunciados na comunicação verbal." (FREITAS, 2007, p. 36). Assim, parafraseando essa autora, a entrevista se caracteriza como uma relação entre os sujeitos e suas experiências sociais e culturais, que eles compartilham com outras pessoas do ambiente ao qual se referem.

Para a coleta de dados, optamos pela entrevista narrativa, porque esta "tem em vista uma situação que encoraje e estimule um entrevistado [...] a contar a história sobre algum acontecimento importante de sua vida e do contexto social.” (BAUER; GASKELL, 2002, p. 93). As entrevistas foram gravadas em áudio e transcritas seguindo as convençóes propostas por Marcuschi (1986). A questão desencadeadora foi: "No seu município já foi implantado o Ensino Fundamental de nove anos. Fale um pouco sobre isso." A partir desse comando, os gestores enunciaram suas experiências.

A análise a que se procederá de alguns desses enunciados parte de compreensóes tecidas pelo Círculo de Bakhtin para o qual "as ciências humanas constituem uma forma de saber dialógico em que o intelecto está diante de textos que não são coisas mudas, mas a expressão de um sujeito." (FARACO, 2003, p. 42). Isso sinaliza para uma atitude responsiva-ativa, na qual o pesquisador ouve e compreende o sujeito pesquisado, estando ambos em interação para a construção de sentidos possíveis em um certo tempo-espaço. O sujeito, nessa perspectiva, é compreendido como um feixe de relaçóes sociais. Diante disso, "considerar a pessoa investigada como sujeito implica compreendê-la como possuidora de uma voz reveladora da capacidade de construir um conhecimento sobre a sua realidade que a torna co-participante do processo de pesquisa" (FREITAS, 2007, p. 29).

No que concerne às Ciências Humanas, Bakhtin (2003, p. 400) alerta que esta se distingue das ciências exatas que "são uma forma monológica do saber", nas Humanas o objeto é o discurso, ou seja, mais que um objeto falado, tem-se um objeto falante. Ao analisar o enunciado, o analista realiza um gesto de interpretação e deve considerar a palavra em sua inteireza: “o que compreende seu aspecto concreto-palpável (morfossintático e 
fonológico), seu aspecto semântico-conceitual e seu aspecto axiológico (seu tom avaliativo)" (FARACO, 2003, p. 27).

Pontuados os aspectos metodológicos e as intençóes que orientam esta pesquisa, passamos a apresentar um breve estado da arte, o que revela que a preocupação em investigar esse tema vai além dos limites pessoais que se apresentaram ao início desta seção. Para tal, foram consultadas as seguintes fontes: Biblioteca Digital Brasileira de Teses e Dissertaçóes (BDTD), o GT 10 da ANPED e os eixos 3 e 11 da ANPEDSul. Foram localizadas as pesquisas de Abreu (2009) e de Dietrich (2008). A primeira investigou as práticas de alfabetizaçáo e letramento no primeiro ano do Ensino Fundamental de nove anos com o foco voltado para os alunos e as professoras alfabetizadoras de Uberlândia - MG. A segunda realizou um projeto piloto para a alfabetizaçáo do ensino de nove anos em Pelotas-RS. Entretanto, pesquisas sobre as compreensóes de gestores educacionais acerca das concepções de alfabetização e letramento no primeiro ano do novo ensino não foram localizadas.

O cenário no qual a pesquisa se insere é mais amplo do que o descrito até aqui, por isso as seçôes que seguem irão ajudar a estabelecer um diálogo entre as compreensóes dos gestores em seus enunciados, os aspectos legais da implantação do Ensino Fundamental de nove anos e outras discussōes tecidas por pesquisadores como Cassany (2005), Rojo (2000, 2006, 2008), Kleiman (1995, 2001, 2008), Bunzen (2010), Schneuwly; Dolz (1999), Street (2003), Dionísio (2007a), Soares (1998, 2003), Cook-Gumperz (2002), Heath (1982).

\section{Ensino Fundamental: os discursos da lei e seus ecos}

Um novo cenário no ensino brasileiro se estabeleceu a partir da Lei Federal 11.274, de 06 de fevereiro de 2006 (BRASIL, 2006-2007), que ampliou o Ensino Fundamental para nove anos de duração, com a matrícula de crianças de seis anos de idade e estabeleceu prazo de implantaçáo pelos sistemas (público e privado) até 2010. Esta Lei é a que "estabelece as diretrizes e bases da educação nacional, dispondo sobre a duração de 9 (nove) anos para o ensino fundamental, com matrícula obrigatória a partir dos 6 (seis) anos de idade." (BRASIL, 2006-2007). Entre as finalidades da sua implantação, conforme as orientaçôes oficiais, está a de incentivar o 
aluno a buscar maiores níveis de aperfeiçoamento, bem como oferecer mais oportunidades de aprendizado durante a escolaridade obrigatória:

O objetivo de um maior número de anos de ensino obrigatório é assegurar a todas as crianças um tempo mais longo de convívio escolar, maiores oportunidades de aprender e, com isso, uma aprendizagem mais ampla. É evidente que a maior aprendizagem não depende do aumento do tempo de permanência na escola, mas sim do emprego mais eficaz do tempo. No entanto, a associação de ambos deve contribuir significativamente para que os educandos aprendam mais. (BRASIL, 2004, p. 16).

A antecipação na idade da entrada da criança no Ensino Fundamental suscitou discussóes sobre como essa criança será recebida na escola, pois, de acordo com as próprias orientaçóes, a escola deverá se adequar a esses sujeitos. Portanto, a alteração do tempo e da idade escolar requer mudanças pedagógicas e estruturais no sistema de ensino. Como ressaltam as Orientaçóes Gerais do ensino de 9 anos,

[...] não se trata de transferir para as crianças de seis anos os conteúdos e atividades da tradicional primeira série, mas de conceber uma nova estrutura de organização dos conteúdos em um Ensino Fundamental de nove anos, considerando o perfil de seus alunos. (BRASIL, 2004, p. 16).

Ao refletir sobre essas questóes, percebemos a necessidade de compreender a discursividade que permeia as orientações, discussóes e formação docente nas secretarias municipais de educação.

Por considerarmos o papel do outro na cadeia enunciativa, o enunciado é representado por ecos, pois "as palavras dos outros trazem consigo a sua expressão, o seu tom valorativo que assimilamos, reelaboramos e reacentuamos" (BAKHTIN, 2003, p. 295). Isso possibilita admitir que os ecos dos discursos presentes nos documentos oficiais perpassam os enunciados dos gestores educacionais (os quais serão identificados com a letra G seguida de números de 1 a 6). Por exemplo, G3 se aproxima das orientaçóes oficiais quando enuncia: 
"[...]' mas hoje nós temos escolas NÂOO da no::ssa re::de né" mas eles acabam alfabetizando 'e::les transcreve::ram simplesmente o curriculo do primeiro ano né "o que é da anti::ga primeira série pro primeiro a::no 'e nós não nós temos uma propro::sta né então a mais de:: é::/ você começa a alfabetiza sim mas aos pouquinhos' CONFO::RME a criança vai e MAIS com o lú::dico[...]"

Ao se referir à organização curricular do primeiro ano (currículo do primeiro ano; nós náo nós temos uma proposta), o gestor sinaliza para a necessidade da organização do trabalho escolar nos anos iniciais levando em conta a compreensão do que seja alfabetizar e quando fazê-lo. Quanto a isso, o gestor afirma que algumas escolas acabam alfabetizando. No caso de nossa pesquisa, no que tange aos aspectos curriculares, é importante esclarecer que, nos municípios menores, nos quais, segundo os gestores, não há conselho municipal de educação, são as orientaçóes da Secretaria de Educação estadual que norteiam a implantação e organização do Ensino Fundamental:

"a maioria dos mun/ e::sses municipios peque::nos aca::bam acatando as normas do esta::do 'a::qui até a gente va::i:: tá se organiza::ndo pra pode:: criar um sistema pró::prio' mas até então:: tem que vê:: se É viá::vel a criação de um siste::ma próprio ou a manutençâo do:: do esta::do.”(G5, p. 3).

"é o esta::do que manda pra nó::s 'atravé::s da:: da gere::d 'porque nó::s aqui [...] é municipa::l mas a gente ainda se::gue as le::is do esta::do né " a gente não tem o plano de ensino PRÓPRIO né " a gente se::gue o estado." (G6, p. 1).

O primeiro sujeito se refere à adequação do município em relação às normativas estaduais, levando em conta a sua realidade, quando diz que o município está se organizando pra pode criar um sistema próprio; já o segundo gestor se posiciona como aquele que recebe: estado que manda pra nós. Quando questionados a respeito da concepção de letramento e alfabetização que fundamenta a proposta de seu município e, por consequência, a estadual catarinense, os gestores sinalizaram desconhecimento. Em outros momentos da entrevista, ao se referirem a questôes de metodologia ou de formação docente, essa discursividade é retomada. A proposta curricular de Santa Catarina, no que tange a esse tema, apresenta o seguinte posicionamento: 
Os conceitos de alfabetização e letramento impóem ação pedagógica nessa perspectiva. Ou seja, a de que a alfabetização é elemento essencial do letramento que orienta o indivíduo para que se aproprie do código escrito, aprenda a ler e escrever e ao mesmo tempo conviva e participe de práticas reais de leitura e escrita. (SANTA CATARINA, 2005, p. 24).

A compreensão das relaçóes entre a aprendizagem do sistema escrito e a inserção na cultura escrita se aproximam nas orientaçóes curriculares. Entretanto, os sentidos desses dizeres são múltiplos e os gestores vão traçando outros caminhos metodológicos para seus municípios, ainda que seu discurso, construção singular, seja compreendido pelo enunciador como uma obediência ao discurso oficial.

\section{Letramentos múltiplos: letramento escolar e suas relações}

O processo de alfabetização é antigo e acompanha a história da escrita. O homem, desde os primórdios, sentia a necessidade de registrar os acontecimentos do seu meio, as suas emoçóes e as suas necessidades. Tudo o que acontecia no dia a dia era registrado através de um código, o qual, segundo Cagliari (1999, p. 12), estava atrelado a uma maneira de aprender e ensinar:

Quem inventou a escrita inventou ao mesmo tempo as regras da alfabetização, ou seja, as regras que permitem ao leitor decifrar o que está escrito, entender como o sistema de escrita funciona e saber como usá-lo apropriadamente. A alfabetização é, pois, tâo antiga quanto os sistemas de escrita. De certo modo, é a atividade escolar mais antiga da humanidade.

Portanto, a importância de conhecer o código escrito segue em um fio histórico, no qual, até um determinado período, o que prevalecia era o domínio do código, mas o uso social desse conhecimento não tinha muito espaço na sala de aula. No contexto atual, é necessário mais que o conhecimento e o reconhecimento de grafemas e fonemas para que o indivíduo participe ativamente da vida em sociedade, formulando hipóteses e 
compreensões sobre o sistema de funcionamento da língua escrita. É preciso que o aluno, antes do início da sua vida escolar, compreenda a função social atribuída à leitura e à escrita, isto é, faça parte de práticas de letramento. Este é compreendido como um "conjunto de práticas sociais que usam a escrita, como sistema simbólico e como tecnologia, em contextos específicos, para objetivos específicos" (KLEIMAN, 1995, p. 18). A teoria acerca do letramento presume ainda que a escrita traz consequências sociais, culturais, políticas, econômicas, cognitivas e linguísticas tanto para o indivíduo envolvido no seu aprendizado, quanto ao grupo social em que esteja inserido (SOARES, 1998). É entendido, enfim, como o envolvimento de gêneros discursivos/textuais com as práticas sociais, um movimento plural, que integra várias linguagens.

A esse respeito, Rojo (2008, p. 585) ressalta que "um dos objetivos principais da escola é justamente possibilitar que seus alunos possam participar das várias práticas sociais que se utilizam da leitura e da escrita (letramento) na vida da cidade, de maneira ética, crítica e democrática." A autora está se referindo aos multiletramentos ou letramentos múltiplos. Segundo Cassany (2005), atualmente existem três novas formas de letramento: o multiletramento, o biletramento e a criticidade. $\mathrm{O}$ primeiro está relacionado às diversas atividades que realizamos com a leitura e a escrita tendo em vista a variedade de textos que lemos em curtos espaços de tempo. Ao refletir sobre a alfabetização, percebemos que está vinculada às relações de poder e ao prestígio social. Não obstante, as práticas de letramento vão além, compreendem o sujeito como um ser social inserido em uma sociedade grafocêntrica.

A escola, como esfera social primordial e inegável, possui práticas múltiplas de letramento, que estão presentes nos mais variados gêneros e linguagens, porém, muitas vezes, o foco da escola não está na relação entre letramento e escolarização, como se a instituição escolar não fosse uma esfera de relaçóes sociais. Para Rojo (2000, p. 5):

A própria necessidade de se distinguir qual a variável determinante das construçóes, se o letramento ou a escolarização, parece-me indicativa desta falta de foco, determinada, talvez, por uma falta de perspectiva histórica. Cabe lembrar que a escola tal qual a conhecemos - sobretudo a leiga, pública e universal 
- é fruto de uma história bastante mais longa de letramento e cultura da escrita, de imprensa e de impressos tornados democraticamente disponíveis e de divisão do trabalho competitivo numa perspectiva do liberalismo.

Portanto, as práticas escolares são também práticas de letramento, mesmo que sejam consideradas tradicionais. Todavia, levar em conta a cultura dos alunos e o meio no qual eles estáo inseridos proporcionaria o desenvolvimento de práticas de letramento ideológico. Este conceito está baseado nos estudos desenvolvidos por Street (2003). Kleiman (1995, p. 21), ancorada nos novos estudos do letramento, argumenta que o letramento, no modelo ideológico, leva em conta "os significados específicos que a escrita assume para um grupo social [...]" Ideia consonante à de Dionísio (2007a, p. 1), que compreende as práticas de letramento ideológico como

[...] um conjunto flexível de práticas culturais definidas e redefinidas por instituiçôes sociais, classes e interesses públicos em que jogam papel determinante as relaçóes de poder e de identidade construídas por práticas discursivas que posicionam o sujeito forma de aceder, tratar e usar os textos e os artefactos e tecnologias que os veiculam e possibilitam.

O indivíduo que está inserido em práticas de letramento é parte integrante da sociedade, compreendendo e vivenciando as práticas de linguagem que estão a sua volta. A inserção no universo da cultura escrita é feita em movimentos dialógicos que levam o sujeito de uma esfera a outra, pois, como afirma Bakhtin (2003, p. 261): "Todos os diversos campos da atividade humana estão ligados ao uso da linguagem. Compreende-se perfeitamente que o caráter e as formas desse uso sejam tão multiformes quanto os campos da atividade humana [...]" Um desses campos é a escola, a qual pode ser compreendida como uma agência que legitima mais que o uso da língua escrita, desenvolve ou adere a metodologias que focalizam alguns aspectos do que está em movimento relacional na cultura escrita. Para construir essa compreensão de práticas sociais, a escola, os professores e seus atores, nesta pesquisa, mais especificamente os gestores educacionais, precisam trazer à baila os pertencimentos teóricos que articulam as propostas 
curriculares e a formação de professores.

Para que haja um gesto de interpretação sobre os enunciados, é preciso que o pesquisador assuma seu lugar enunciativo. Nessa tentativa de assumir um olhar para o outro, algumas escolhas se fizeram necessárias. A primeira delas diz respeito à maneira como a alfabetização é compreendida em relação ao letramento. Posto isso, será importante analisar também o que os gestores enunciam sobre: o papel do primeiro ano, as metodologias no fazer docente, o funcionamento da escola e o papel do professor nesse novo cenário.

\section{Relações entre alfabetização e letramento: sentidos e contextos}

O uso dos termos alfabetização e letramento já sinaliza para uma perspectiva de que são conceitos distintos, os quais, na maioria das vezes, são compreendidos como dicotômicos ou, ainda, como em um processo no qual é preciso que ocorra primeiro um para que depois o outro possa vir. Estabelecer distinçóes e posicionamentos teóricos quanto aos termos é importante; o que deve ser problematizado, no entanto, é como esse discurso atinge os atores educacionais. Na maioria dos enunciados, circula uma compreensão dicotômica entre alfabetizar e letrar, um exemplo disso é o que o responsável pelo Ensino Fundamental de um dos municípios comentou durante a entrevista:

"o município até um certo tempo adotou o método alfa:: e beta né "? [...] já houve há um tempo atrás a:: se eu não me engano foram dois anos atrás discussóes sobre LETRAME::NTO tá:: mas ai é como eu lhe digo eu não tenho né:: nós temos alguma coisa da proposta que foi escrita até [...]" (G1, p.5).

O enunciado sinaliza que, no caminhar das gestóes educacionais, houve, em um momento, opçóes por métodos, neste caso o fônico, cuja unidade de ensino é o fonema e, por conseguinte, suas relaçóes com os grafemas; em outro tempo de gestão, apresentaram-se conversas sobre letramento e, como consequência, houve o apagamento do uso de métodos. Bunzen, aos discutir dicotomias como essas, alerta para a necessidade de problematizar relaçóes como as que se apresentam entre letramento e escolarização, pois, segundo ele: 
Ao romper com essa visão dicotômica, assumimos que grande parte das práticas sociais escolares são sustentadas por práticas orais ou escritas em que o texto multissemiótico desempenha um papel central (KLEIMAN 1998; ROJO, 2001). Por isso, o termo letramento escolar náo deveria a priori ser utilizado como algo necessariamente negativo ou perverso, autônomo e estático por natureza, mas como um conjunto de práticas discursivas da esfera escolar. (BUNZEN, 2010, p. 100).

Nessa esteira de reflexão, há aproximações entre alfabetização, letramento e escolarização, pois, como já aventamos antes, a escola é a principal agência de letramento. Rojo (2000, p. 6, grifos da autora) afirma que "escola é letramento e dele decorre, quer suas práticas sejam orais ou escritas; quer haja ou não texto escrito sendo utilizado na sala de aula. Logo, só é admitida uma estrutura adjetiva: 'letramento escolar.'”

Aprofundando a reflexão, a alfabetização pode ser compreendida como uma etapa do letramento escolar, pois o processo de inserção na cultura escrita se dá pela descoberta do que foi registrado por outros interlocutores, num desafio de compreender o que o texto escrito traz em si e quais as razóes que moveram o autor a se posicionar dessa ou daquela forma a respeito do que está dito. Para além do registro escrito que as linhas trazem, o leitor também pode ingressar no contexto mais amplo que leva à produção. Para que as relaçóes entre texto e leitor aconteçam, há que haver o ensino e a aprendizagem da própria leitura e da escrita. Isso aponta para um letramento escolar que ocorra em processo. Alguns gestores, ao se referirem à alfabetização, enunciam uma compreensão de que há um processo que antecede e precede o ano de ingresso da criança no Ensino Fundamental:

"entende::mos que o processo de alfabetização já:: começa lá:: no estágio UM da educação infanti::l' né" quando a gente LÊ pra cria::nça' quando ela tem acesso a li::vros de:: de:: de teci::dos' de papelã::o' qua::ndo ela já brinca com revi::stas e faz movime::ntos de folhar REVI::STAS enfim' isso já tu::do faz parte do proce::sso de alfabetizaçâo' mas eu estou aqui:: me referi::ndo àquele proce::sso mais forma::I né" é:: ma::is é:: que que que é de responsabilida::de dos anos inicia::is do ensino fundamenta::l' entã::o nós não temos/ então a discussã::o te::m que passar por ai::'o QUE QUE a ge::nte faz" que ambie::nte a gente 
ofere::ce" pra e::ssa criança do primei::ro a::no' na VERDADE as nossas crianças continua::ram tendo as ativida::des que e::las ti::nham no prezi::nho 'tá " só que a gente vinculo:: ao ensino fundamenta::1 .” (G4, p. 2).

"nós busca::mos é sempre trabalhar a questão DA REa::lida::de’ da questão da CONSTRUÇÃO da criança nesse processo de aprendiza::gem e pra nós isso é até mais fácil porque são turmas pequenas né" então assi::m os nossos professores te::m menos crianças' a::s escolas que são multisseriadas os alu::nos de primeira série JÁ ouvem os que de segunda estáo conversa::ndo os que de terceira:: então há uma troca muito gra::nde e a gente trabalha também com a questão de monitorame::nto os alunos de:: QUARTA série por exemplo auxiliam os de prime::ira em momentos/ em ce::rtos momentos da aula [...] há HÁ o REFORÇO CONTÍ::NUO de aprendiza::gem." (G2, p. 3).

Ainda que os gestores não empreguem o termo letramento, o que se depreende é uma compreensão de diálogos entre espaços, tempos e interlocutores. Ao dizer "no estágio UM da educação infantil quando a gente $L \hat{E}$ pra criança”, G1 sinaliza para o alargamento da dimensão espaçotemporal de inserçáo da criança na cultura escrita através da participação em eventos de letramento (HEATH, 1982). O outro gestor, ao se referir à dinâmica das aulas na escola multisseriada, traz à tona a possibilidade de interlocução entre alunos de diferentes séries/anos, em uma perspectiva que rompe com um currículo de conteúdos arraigados ao seu tempo escolar. No diálogo entre os alunos, todos se tornam capazes de ensinar, pois "os alunos de primeira série JÁ ouvem os que de segunda estão conversando os que de terceira então há uma troca muito grande."

Essa reflexão se insere na compreensão da linguagem como dialógica e isso aponta para sentidos que se constroem na interação com o outro. Bakhtin (1992) ressalta a importância da palavra em função do interlocutor, tendo em vista que esta comporta duas faces. Dessa forma, é na relação entre quem diz e quem com ele faz a interlocução que os sentidos são construídos. A metáfora da ponte, proposta pelo autor, mostra os pontos que se ligam, locutor e interlocutor, no território comum que é a palavra. Pensar em pessoas em interaçáo remete à situaçáo social. Quanto a isso, afirma o autor "a situação social mais imediata e o meio social mais amplo determinam completamente e, por assim dizer, a partir do interior, a estrutura da enunciação" (BAKHTIN, 1992, p. 113). A enunciação é, 
portanto, o produto da interação de dois indivíduos socialmente organizados. Completando esse pressuposto, valemo-nos de mais uma metáfora do autor: "A enunciação realizada é como uma ilha emergindo de um oceano sem limites, o discurso interior. As dimensões e formas dessa ilha são determinadas pela situação da enunciação e por seu auditório" (BAKHTIN, 1992 , p. 125, grifos do autor). Deste modo, a expressão exterior é a realização do discurso interior, o qual foi conformado pela situação e pelo auditório. Ao se inserir no contexto náo verbalizado, a expressão exterior vai sendo inundada pela vida que a cerca, como o mar cerca a ilha, fazendo com que seja ampliada tendo em vista os gestos, a ação, a resposta dos outros que compartilham a mesma situação enunciativa.

Partindo dessa ideia e observando o espaço da sala de aula, onde há interação verbal, é possível também compreender como a forma e o estilo da enunciação são determinados pela situação e pelos participantes. Diante disso, para falar da aprendizagem durante o processo de alfabetização/letramento, é preciso considerar que a conduta da criança será compreendida se ela não for isolada do meio em que se manifesta. Para tanto, são necessárias, por um lado, informaçóes sobre o meio familiar e o segmento social da criança e, por outro, informaçóes sobre a interação da criança nas diversas situações escolares, obtidas por meio de observação do educador, que poderá perceber a dinâmica da interação da criança com o grupo e com o professor. No processo de aprendizagem em que a criança se envolve, é importante a figura do outro, o que faz crer que, quanto maior a diversidade dos grupos de que a criança participar, mais numerosos serão seus parâmetros de relaçóes sociais.

Sendo o dialogismo o princípio constitutivo da linguagem, acreditando-se que a enunciação é o resultado da interação entre locutor e interlocutor, pode-se, então, perceber o espaço escolar como o de negociaçáo de sentidos. Dessa forma, pensar o processo de alfabetização/letramento aponta para a inserção no mundo do texto e não das unidades menores como fonemas, grafemas, sílabas e palavras. Compreender o sistema escrito, nessa perspectiva, não é apenas reconhecer o sinal sonoro ou escrito, preocupandose com as relações fono-grafêmicas e grafo-fonêmicas. A linguagem está em movimento e este deve se fazer sentir no processo de inserção na escola e nos momentos dedicados à aprendizagem da leitura e da escrita.

A discussão sobre letramento traz em si uma outra: a de concepção de linguagem, a qual foi pontuada ao longo do texto. Em alguns espaços 
de gestão, a perspectiva teórico-metodológica entra na roda das discussóes, especialmente quando os atores educacionais, mais especificamente gestores e professores, estão em processo de (re)elaboração de proposta curricular.

"letramento né:: e:: eu penso assim ó que essa coisa dos gêneros né:: isso tem que trazer muito à baila né " muito pral não é ne::m trazer pra discussão é subsidiar MESMO'é explicá:: é dizer pro professor né:: por que que eu uso tal texto o que que eu quero com tal texto qual a minha possibilidade né "e:: isso vai tá::/ nos próximos três anos a gente tem ideia de terminar e assim ó vai trazer na propro::stal a gente tem pensado em fazê-la agora â:: é ter um núcleo comu::m que seria né "o que se pretende e os conceitos bá::sicos 'e a avaliação e:: metodologia e aí depois então tá abrindo para as disciplinas ou AREAS isso a gente não tem bem definido né:: entã::o fazer nesse caderno querendo ou não nós ainda pensamos tá:: em tá estruturando com algumas a::tividades certo e:: assim né " elaborar umas quatro ou cinco atividades mas TRAZE::NDO né " pro professor é tudo o que permeia essa atividade né" e vai além de só ta:: copiar um rótulo 'de só recortar' de só identificar na revi::sta né:: ou de escrever o bilhete pelo bilhete né:: porque:: o que passa é isso é:: o bilhete pelo bilhete né:: qué dizer a não mas eu ensino a não mas eu né" mas é:: que significado tem né "como que fica isso" né" como eu dou consistência pra isso "como e::le reelabora com ele né "pra tá usando no dia a dia né "enquanto gente comé que ele via usá isso:: né" em que circunstância ele vai tá usando né" isso tá claro ou não."(G1, p.7).

A posição enunciativa desse sujeito revela a sua constituição a qual é permeada tanto pelo discurso da sala de aula, na qual ele já atuou como professor, como pelo discurso dos órgáos oficiais, que o atinge enquanto responsável pela organização do Ensino Fundamental dentro de uma nova proposta e pela orientação pedagógica do docente. Essa discursividade circulante lhe pede uma resposta, que vem na forma de preocupação com o fazer docente dentro da perspectiva dos gêneros discursivos (que essa coisa dos gêneros, isso tem que trazer muito à baila; vai além de só copiar um rótulo). A inserção de gêneros de linguagem está em articulação com as práticas de linguagem, as quais "implicam dimensóes, por vezes, sociais, cognitivas e linguisticas de funcionamento da linguagem numa situação comunicação particular" (SCHNEUWLY; DOLZ, 1999, p. 6, grifos do autor). A opção por um fazer pedagógico que se ancore nas práticas de linguagem requer 
um olhar para além dos espaços escolares, pois "estudar o funcionamento da linguagem como práticas sociais significa, então, analisar as diferenciaçóes e variações, em função de sistemas de categorizações sociais à disposição dos sujeitos observados" (SCHNEUWLY; DOLZ, 1999, p. 6).

Decorrente da discussão sobre a organização curricular dos anos iniciais dentro da nova legislação, há que se pontuar que a concepção de linguagem que embasa a proposta de cada município pode delinear as outras formas de organização e a escolha do objeto de ensino. Essas escolhas teórico-metodológicas vêm acompanhadas de outra preocupação que está presente nos enunciados de professores, conforme verificaram Heinig e Stolf (2008), e também dos gestores. Afinal, qual o objetivo do primeiro ano no que concerne à leitura e à escrita?

\section{O primeiro ano (não) é para alfabetizar?}

Ao serem convidados a falar sobre a implantação do Ensino Fundamental de nove anos, a maioria dos gestores, logo no início da conversa, referiram-se ao papel do primeiro ano no processo de alfabetização. G2 aponta para "a questão diga::mos de:: de de pensar em alfabetização não::/ digamos assi::m (a:: mais) primeira série alfabetização ma::s a alfabetização é pensada no novo sistema de avaliaçâ:::o." Este dizer está em consonância com o que sugere G3 sobre o trabalho com o primeiro ano, quando diz que o "objetivo inicial não era alfabetiza:: 'era fazer essa socializaçã::o ' mas hoje nós temos escolas $N A \tilde{O}$ da no::ssa re::de né " mas eles acabam alfabetizando [...] você começa a alfabetizar sim mas aos pouquinhos 'CONFO::RME a criança vai e MAIS com o lú::dico né." G4 também sugere que, no primeiro ano, o foco não está na alfabetização: "o primeiro a::no NÂAO É pra alfabetizá:: [...] esse é o nosso OBJETI::VO ao final do SEGU::NDO A::NO. O sujeito G5 afirma: só que tem um problemi::nhá assi::m 'a gente perce::be que os no::ssos professores 'e::les 'a::té já falei em outras reunióes também pra eles 'eles se preocu::pam DEMA::IS em querer que o alu::no realmente APRENDA:: e seja alfabetiza::do JÁ na pré esco::la 'pra depois quando cheguem no primeiro a::no eles já dominem esse conteúdo 'e essa não É a mentalida::de que o esta::do te::m 'o esta::do diz que o primeiro a::no é pra trabalha:: a parte LÚ::DICA [...]' Partindo da entonação expressivo-valorativa e das palavras dos gestores, dois aspectos se fazem sentir nesses dizeres: um se refere à compreensão do que 
seja alfabetizar e outro envolve as questóes relativas à avaliação do aprendiz da escrita e sua atuação no primeiro ano.

Alguns autores, entre eles Soares (1998; 2003) e Morais (2006), definem a alfabetização como técnica de aprender a ler e escrever. Nesse sentido, Dionísio (2007b, p.4) faz a seguinte afirmação: "se considerarmos a alfabetização como o processo de dotar os indivíduos dos códigos relativos ao escrito, para os momentos reservados de aprendizado do código escrito, podemos falar que alfabetização - é aprender o código escrito.” É nessa concepção que circulam também os dizeres dos gestores acerca de que o primeiro ano não é, especificamente, o espaço de alfabetização, como enuncia G4: "o primeiro a::no NÂO É pra alfabetizá:: [...] esse é o nosso OBJETI::VO ao final do SEGU::NDO A::NO 'que é a anti::ga primeira série.” Este dizer aponta para os limites de cada ano, não levando em consideraçáo o processo de letramento que ocorre nesse período. Não há como, numa perspectiva social, dissociar alfabetização de letramento, estabelecendo tempos para que cada aprendizagem ocorra. Afinal, trata-se de sujeitos inseridos em uma cultura escrita. Por mais que se deseje adiar a aprendizagem da leitura e da escrita, uma vez inserido em contexto de letramento, o sujeito já estará apreendendo sobre as funçóes sociais que ler e escrever têm em uma sociedade grafocêntrica. Kleiman (1995, p. 20, grifos do autor), avaliando o papel da escola no que concerne ao letramento, afirma que:

O fenômeno do letramento, então, extrapola o mundo da escrita tal qual ele é concebido pelas instituiçóes que se encarregam de introduzir formalmente os sujeitos no mundo da escrita. Pode-se afirmar que a escola [...] preocupa-se, não com o letramento, a prática social, mas com apenas um tipo de letramento, a alfabetização, o processo de aquisição de códigos (alfabético, numérico), processo geralmente concebido em termos de uma competência individual necessária para o sucesso e promoção da escola.

Por outro lado, os enunciados dos gestores sinalizam uma lacuna no que concerne ao currículo dos anos iniciais do Ensino Fundamental, 
bem como à avaliação que deriva da concepção de linguagem e educação presentes nas propostas de cada município. Nas orientaçóes para os anos iniciais do ensino de nove anos (BRASIL, 2007), a perspectiva que se apresenta é de que a aprendizagem deva ocorrer em um contínuo a fim de que o aluno desenvolva habilidades e capacidades que estão organizadas em cinco eixos distintos e interligados: compreensão e valorização da cultura escrita; apropriação do sistema de escrita; leitura; produção de textos escritos; desenvolvimento da oralidade. Portanto, cabe aos gestores, na sua atuação, também a discussão acerca das orientaçóes curriculares, possibilitando aos professores a compreensão do que deve ser considerado nesse processo que inicia no primeiro ano e prossegue não só na escola, mas também em outras agências de letramento. Por outro lado, concordamos que:

De fato, não é simples selecionar o que ensinar no ensino fundamental, mas precisamos refletir sobre quais saberes poderão ser mais relevantes para o convívio diário dos meninos e meninas que frequentam nossas escolas e para a sua inserção cada vez mais plena nessa sociedade letrada, pois eles têm o direito de aprender os conteúdos das diferentes áreas de conhecimento que lhes assegurem cidadania no convívio dentro e fora da escola (LEAL; ALBUQUERQUE; MORAIS, 2007, p. 97-98).

Articulando a discussão sobre qual o melhor momento para a alfabetização às questóes que circulam em torno do currículo, surge um outro ponto que nos parece importante para que esses aspectos sejam discutidos e organizados em cada gestão: as questóes metodológicas e os saberes docentes. Mas antes de nos aventurarmos nessa courela, achamos importante relembrar o que Street (2003, p. 5) diz sobre o engajamento no letramento, considerando-o:

sempre um ato social, desde o seu início. As formas em que interagem professores ou facilitadores e seus alunos é sempre uma prática social que afeta a natureza do letramento a ser aprendido e as idéias que os participantes possam ter sobre o processo, em especial os novos aprendizes e sua posição nas relaçôes de poder. 
Portanto, discutir as questóes metodológicas é mais que tomar decisóes quanto ao fazer pedagógico que orientará a técnica de ensinar e aprender sobre a escrita, é ingressar em um campo enunciativo no qual os interlocutores estão em processo de construção de conhecimentos, de negociação de sentidos e de disputa por poder.

\section{O olhar do gestor para o fazer pedagógico}

As compreensóes de letramento e alfabetização oscilam de acordo com o momento histórico em que cada gestor (também professor) se formou e de acordo com orientaçóes que distintas gestóes das secretarias de educação foram articulando. Mas, percebe-se que, muitas vezes, falar em alfabetização é fazer referência a um método, pois, como já foi comentado inicialmente, desde o início da história da aprendizagem da escrita, foram desenvolvidos aspectos referentes a como se ensina. Por outro lado, parece haver um temor em fazer referência a um método específico, denominando-o. Como é que esses discursos e saberes acerca de como ensinar foram se constituindo? Parafraseando Tardif (2002), o professor, em suas relaçóes humanas, torna-as profissionais quando atribui um sentido próprio aos momentos de relacionamentos na sua vida pessoal, os quais, carregados de uma subjetividade, transpóem elementos para uma coletividade que se configura como grupo de aprendizagens mútuas. Assim, pode-se perceber a identidade profissional docente como um processo contínuo que se vincula à identidade pessoal, ligada a distintas categorias, entre elas a social e a pessoal, possibilitando construir, desconstruir e reconstruir sentidos para sua vida e seu trabalho. Os enunciados que serão apresentados aqui foram construídos nesse diálogo entre as diferentes fontes de saber que, aos poucos, constituíram o profissional da educação, e este, por assumir uma posição nesse campo, manifesta-se por uma ou outra maneira de conduzir o seu fazer, às vezes, aproximando e outras negando opçóes metodológicas.

Alguns gestores citam o método ou fazem referência a como ele é observado na dinâmica da sala de aula. G1 menciona, em um momento, a presença do método silábico: "continuamos usando o ba be bi bo bu o ca co cul o ca ce ci/ já nem mais CA CE CI CO CU e assim por diante quer dizer (+) não mudou nada nê", nós temos mais um ano e mais [...]". Quando questionado sobre a adoção de algum método, o sujeito relembra a adoção, na gestão 
anterior, do método fônico, especificamente o alfa e beta. Entretanto, ao se referir ao trabalho com o primeiro ano, o seu posicionamento é outro e afirma que "cada esco::la' cada professo::r nê"? usa dos seus conhecimentos ce::rto"? é:: já passamos em algumas escolas onde né:: começam por ró::tulos né:: começam comé pelo no::me [...]" e retoma, depois de algum tempo, a questão sinalizada no início da entrevista: "passamos por escolas onde é:: nós já vimos né:: a:: comé as famílias silábicas ce::rto então vamos dizassim/ não tenho pra te dizer assim no momento né:: não há um padrão único não há uma li::nhá né única." Para além disso, o gestor alia, ao fazer dos professores, o que considera uma perspectiva de letramento e completa o que enunciou anteriormente: "o que a gente vê é que entendl nê"? já trazem no seu traba::lho é:: algum entendimento da questão nê" de letramento né:: tão traze::ndo né" pra esse lado e:: usam a literatu::ra ce::rto ma::s é:: ou::tros ainda sa::be permanecem e:: eu penso que até por se sentirem seguros também NE." O que se pode inferir desse amálgama discursivo é que o gestor leva em conta, por um lado, os fazeres e saberes dos professores e, por outro, se vê atingido pelo discurso oficial que orienta o Ensino Fundamental de nove anos. Como, no campo de poder em que se encontra, equilibrar as relaçóes entre o discurso oficial e o discurso oficioso? No diálogo entre os diferentes enunciados, esta é uma questão que surge numa atitude responsiva ativa, mas há que se compreender todos os fios dessas relaçóes antes mesmo de se propor um caminho metodológico.

Os enunciados dos gestores trazem também um receio: o de fazer referência a métodos de alfabetização, o que circula é o discurso da liberdade de opção.

“não term um método próprio’ o método que dá CERTO na sala de a::ula’ porque eu acho que não exi::ste um MÉTODO que É o corre:: to' e si::m tem que ver a realida::de de cada cria::nça' como ela já:: vem'o QUE ela traz de ca::sa' qual a bagagem' qual a realida::de de::la’ pra poder tá sendo trabalhada a questão do::s dos no::ve a::nos." (G5, p.1).

“: um método" NÃO:: é:: é norma::l' né" não tem assi::m é:: UM me::todo de alfabetizaçâ::o’ né " é:: o:: norma::l né " o regula::r." (G6, p. 2).

"me::todo na verdade assi::m se eu tivesse que te dize:: TEM nome o método nã::o’ o que nó::s buscamos é tá CONstruindo a aprendizagem com as crianças 
nã::o na perspecti::va do que nos foi passado em anos anterio::res de que nós esquecessemos os li::vros 'carti::lhas." (G2, p. 3).

Para compreender um pouco esse posicionamento, temos que olhar, pelo menos, para dois aspectos: o saber docente e o discurso dos documentos oficiais. Se, no cotidiano da escola, as práticas de sala de aula são conduzidas por saberes vindos da experiência docente e da memória de cada professor sobre como foi alfabetizado, há que se compreender o discurso sobre a liberdade de opção metodológica, delegando ao professor a tomada de decisão. Entretanto, qual o problema em discutir, em uma rede de ensino, uma diretriz que permita um diálogo entre o saber docente e os conhecimentos teóricos? Frade (2003) apresenta uma reflexão sobre como, no percurso histórico do ensino da escrita e da leitura, vários métodos foram se inserindo no espaço escolar e, ao se posicionarem de forma positiva em uma época, provocavam a oposição a outro. Vale relembrar os métodos conhecidos como analíticos ou sintéticos e o que cada um elegeu como objeto de ensino e como descreveu o caminho que professor e aluno deveriam percorrer se desejassem aprender as questóes relativas à decodificação e à codificação. Entre o diálogo e o duelo, na linha do tempo, os métodos foram-se firmando e alcançaram a atualidade ainda que sejam negados. É esse aspecto da negação que ecoa nos enunciados dos gestores e também circula nos espaços educacionais. Mas, o que é método? Partindo da significação, método, originário do grego méthodos, é, segundo Houaiss (2001),

\begin{abstract}
procedimento, técnica ou meio de se fazer alguma coisa, esp. de acordo com um plano; processo organizado, lógico e sistemático de pesquisa, instrução, investigação, apresentação etc.; [...] conjunto de regras e princípios normativos que regulam o ensino ou a prática de uma arte.
\end{abstract}

Se o verbete apresenta termos como procedimento, plano, processo, regras, significa que a realização de uma pesquisa, instrução não pode prescindir de um método. Logo, ainda que não seja nomeado, ainda que seja negado, implicitamente o método está ali.

Caminhando mais nessa discussão, situando-a no espaço da escola e das discussóes sobre as práticas de linguagem, é importante pensar nas implicaçóes decorrentes da instauração de um acordo metodológico. Pois, 
na arena dos sentidos, onde cada um traz suas singularidades, também é possível haver palavras de acordo, numa atitude responsiva ativa ao diálogo que os atores educacionais promovem quando refletem sobre si e seu fazer pedagógico. Para além disso, concordamos com Frade (2003, p. 29), que defende "a ideia de que precisamos recortar e descrever, no conjunto de práticas de letramento, aspectos específicos que provocam um certo sucesso no trabalho com decodificação, para torná-los públicos, sem receio de que uma discussão metodológica seja considerada um retrocesso.”

Essa discussão sobre as questôes metodológicas traz em si uma outra reflexão: o papel do professor e sua atuação em sala de aula. Ser professor é uma construção histórica, pois o sujeito vai criando, ao longo de seu percurso escolar, uma imagem do que seja ser professor (ARROYO, 2001). Essa construção de sentidos se faz a partir das diferentes fontes de saber (TARDIF, 2002), o que possibilita a formação de um professor que traz a sua história repleta de memórias da escola e, por sua vez, singular, e, ao mesmo tempo, um sujeito que, ao ingressar em um espaço educativo, com seus pares, vai aprendendo sobre o funcionamento da escola e suas relaçóes de poder. Nesse misto entre o singular e o coletivo, o professor vai construindo sua identidade docente. Os gestores, ao se referirem à atuação dos professores, trazem alguns pontos interessantes para discussão. G3 e G6, por exemplo, referem-se ao trabalho com projeto, mas com compreensóes diferentes; G1 traz seu olhar de gestor observador para a sala de aula do primeiro ano e faz uma rápida análise do que vem encontrando nesse espaço.

O discurso sobre como trabalhar em sala de aula, em uma perspectiva que foque o texto e/ou o gênero discursivo e considere a participação das crianças, tem levado alguns professores a um trabalho com projetos, como é o caso desse município: " a maiori::a das no::ssas escolas trabalha com te::mas né”? com proje::tos didá::ticos [...] eles colocam TEMAS e em cima daquilo que a criança tem é:: tem afinida::de a gente esco::lhe nê"? e eles vo::tam pra você primeiro eles dão vários te::mas."(G3, p. 3-4).

Essa perspectiva também está presente nos documentos oficiais que norteiam a formação dos professores dos primeiros anos do Ensino Fundamental (BRASIL, 2007). Uma proposta com projetos deve ser compreendida no âmbito mais amplo, no qual a tomada de decisão seja coletiva, em uma negociação entre alunos e professores, envolvendo os desejos e as capacidades e habilidades que são pretendidas para aquele 
momento na organização curricular. Como diz G3: "eles colocam TEMAS e em cima daquilo que a criança tem afinidade a gente escolhe." Depreende-se, pelo uso do termo afinidades, a intenção de incluir os saberes da criança no desenvolvimento do projeto que se dá por temas. Essa preocupação com o outro sinaliza, de um lado, para um trabalho com diversos textos, pois a pesquisa e produção, ao longo do trabalho com projetos, requer isso, e por outro, um olhar sensível ao fazer pedagógico, conforme Osborne (1996). Para além disso, ao pensar no desenvolvimento de metodologias como as que são apresentadas por esse gestor, é importante atentar para o que Kleiman (2008, p. 512) pontua:

\begin{abstract}
Além dos conhecimentos teóricos pertinentes, devidamente ressignificados para a situação de ensino, o letramento para o local de trabalho abrange também conhecimentos sobre as condições específicas de trabalho, as capacidades e interesses da turma, a disponibilidade de materiais e o acesso que a comunidade tem a eles. E, nesse sentido, quanto mais o docente souber sobre o objeto de estudo e a situação comunicativa envolvida, sobre seus alunos e sua bagagem cultural, maiores serão as probabilidades de ele ser capaz de criar situaçóes significativas de aprendizagem.
\end{abstract}

A metodologia de projetos, uma prática que está se instalando no município desse gestor, é uma das possibilidades de levar em conta os letramentos locais, uma vez que o que se tem, como primeira meta, é a inserção na cultura escrita, levando em consideração as práticas de leitura e escrita das quais o aluno participa.

Por outro lado, no município de G6, o fazer pedagógico oscila entre o trabalho de cópia, uma perspectiva mais mecanicista e, por outro lado, com os denominados projetinhos: "eles trabalham basta::nte co::m co::pias né "? e::ssas coisas assim e:: realiza::m projeti::nhos com eles me::smo' a:: tipo:: tá chegando setembro::' aqui:: nós temos a festa da nature::za' então eles desenvo::lvem algu::ns proje::tos' uma co::isa os alu::nos pesqui::sam." Ainda que se fale em projetos, aqui o sentido é outro, mais focado nas datas comemorativas, uma prática corrente na escola por muito tempo. O que se percebe, nesse enunciado, é a introdução de uma outra maneira de trabalhar 
em sala de aula, mas sem perder o que costumeiramente é qualificado como "o que está dando certo", pois houve uma consolidação desse fazer por um certo tempo, no qual o saber da experiência se tornou o lugar de construção acerca de como ensinar nos primeiros anos.

Entre saberes docentes, conhecimentos científicos e fazeres pedagógicos, no que concerne à linguagem e sua escolarização, vale uma reflexão sobre o currículo dentro da perspectiva de letramento. Sobre isso, Bunzen (2010, p. 116) pondera que essa abordagem:

possui algumas limitaçóes/tensóes, especialmente quando adotamos uma abordagem de base sociológica e discursiva para compreender o letramento. [...] a perspectiva curricular, centrada em aspectos metodológicos, volta-se para o "como ensinar" e quase não leva em consideração como são ensinadas e construídas as relaçôes de poder, identidade, crenças e valores sobre a cultura escrita na escola.

Diante disso, percebe-se que ainda há um caminho longo a fim de que se aproximem as compreensóes teóricas do fazer docente, para que se possa, partindo do letramento local, atrelado ao que se discute na academia, propor, coletivamente, discussóes sobre o "como fazer", sem perder de vista o mais significativo no processo de inserção na cultura escrita e na aprendizagem do sistema alfabético. Pois, como observou G1, em sala de aula, quando as propostas não se aproximam do aluno, ele, ainda que presente, afasta-se da sala de aula: 'lá na sala de aula o professor né 'tem 'um quadro che::io de atividades AINda 'PAra um primeiro ano 'e essas atividades estão na questão de copiAR e repetir paLAvras 'o aluno está lá 'muitos ' $n E$ " apoiados na me::sa outros mexendo com o lá::pis outros né" com o pensamento muito [...]". Situações como esta apontam para a formação do professor alfabetizador, como já discutiram Soares (2005), Rojo (2006), Kleiman (1995, 2001). Os discursos sobre alfabetizar e letrar, sobre o trabalho com gêneros discursivos, sobre projetos didáticos têm atingido o professor, entretanto, faz-se necessário que o professor conheça o que implica cada processo. No que tange à formação do alfabetizador, Soares (2005, p. 14) assim se posiciona:

Um alfabetizador precisa conhecer os diferentes componentes do processo de alfabetização e do 
processo de letramento. Conhecer esses processos exige conhecer, por exemplo, as práticas e usos sociais da língua escrita, os fundamentos do nosso sistema de escrita, as relaçôes fonema/grafema que regem o nosso sistema alfabético, as convençôes ortográficas [...] O alfabetizador dá acesso ao maravilhoso mundo da escrita, dá acesso aos livros, à leitura, conduz a criança à conquista do instrumento que lhe abre as portas para todo conhecimento. [...] O alfabetizador tem de conhecer o objeto da aprendizagem e também o processo pelo qual se aprende esse objeto, a língua escrita. Infelizmente esses conhecimentos ainda não entraram na formação dos alfabetizadores.

Nesse cenário investigado, percebe-se que há um desejo de aproximação com o que veicula sobre as práticas de leitura e escrita, mas ainda permanece a contradição existente entre "as concepçôes de ensino da escrita como o desenvolvimento das habilidades cada vez mais abstratas [...] com os modelos que consideram a aquisição da escrita como uma prática discursiva” (KLEIMAN, 1995, p. 47-8). Nesse espaço contraditório e de processo inicial de formação sobre as questóes da linguagem, o professor tenta incluir, no seu fazer, um trabalho com textos, mas ainda não um trabalho com gêneros discursivos. G1, ao comentar visitas a escolas, menciona: “ já passamos em algumas escolas onde começam por rótulos." Rojo (2006), analisando uma aula com rótulo de um achocolatado, observa que a professora somente ao final da aula faz alguma inserção no gênero, e que ela, embora usuária, ao trazer o rótulo para a sala de aula, o reduz, e seu foco fica nas unidades menores como palavras, letras e sílabas. Nos enunciados em que os gestores se referem ao trabalho docente, algumas vezes, percebe-se que ainda não está claro qual o objeto de ensino e, para além disso, o que implica a compreensão de língua e linguagem no trabalho com os anos iniciais, que vai para além dos métodos de alfabetização, mas que precisa ter um caminho metodológico pelo menos acordado entre os que irão atuar junto aos sujeitos que chegam à escola com o desejo de saber mais sobre ler e escrever. Pois, como advoga Bunzen (2010), o letramento escolar deve ser ampliado para além do ensino formal da leitura e da escrita, afinal a escola é um espaço dialógico em que práticas e eventos de letramentos ocorrem. Diante disso, há que se tornar visível a teia de relaçóes entre gestão, formação e avaliação. São mais que 
palavras que rimam, são posturas que podem desencadear um outro olhar para o Ensino Fundamental. Uma tentativa de aproximaçóes é o que relata esse gestor:

"[...] não só pensar em COMO eu vou ensina::r ma::s em como o aluno aprende” porque se eles entendere::m como o aluno aprende:: eles vão sabê como ensiná:: né" entáo ne::sse sentido' é um curso é:: que tá fundamenta::do mais ou me::nos' eu poderi::a dizer assi::m'é:: na:: na:: numa questão metodoló::gica de reflexão ação reflexão né" entã:: o a gente vai estuda::ndo essas novas teori::as' aí eles têm um trabalho PESSOA::L pra FAZ $\hat{E}::$ dura::nte aquela semana COM os alu::nos' aplicá:: tá" ai na:: semana seguinte eles trazem o rela::to reflexi::vo de como foi a aplicaçâ::o dessa ativida::de’ qua::is as dificulda::des que encontrara::m né" qua::is as dúvidas que encontrara::m'e dai isso é discuti::do em gru::po e é avança:: do então sempre reto::ma' ava::nça' reto::ma' ava::nça né" bem lega::l'." (G4, p. 4).

O ensino e a aprendizagem da leitura e da escrita não estão no vácuo, há que se considerar que, primeiro, faz-se necessária a compreensão da concepção de linguagem que subjaz às orientaçôes apresentadas pelas instâncias orientadoras da educação nacionalmente. Para além do que rezam as autoridades, cada localidade precisa levar em conta a sua cultura escrita, bem como os gestores devem discutir juntamente com outros atores educacionais a concepção de infância, de criança e de escola que orienta as ações pedagógicas. Quanto a essa relação, G5, ao não permitir o fechamento das escolas multisseriadas, revela compreender o sentido que a escola tem como lugar identitário: "pra e::les a escola é uma REFERE::NCIA na comunida:: de fechando a esco::la parece até que eles perdem um pouco do:: da identida:: de da própria comunida::de' então eles se negam mu::ito a:: fecha a esco::la."

\section{Considerações ainda preliminares}

O objetivo deste artigo é analisar as relaçóes estabelecidas entre alfabetização e letramento e as suas implicaçóes no fazer pedagógico e na organização curricular no processo de implantação do Ensino Fundamental de nove anos. Os dizeres dos gestores revelam um momento de conflito e indecisão quanto às discussôes e decisóes em torno desse segmento do ensino. De um lado há um novo sistema que foi implantado, de outro há 
novas gestóes educacionais. Nem todos os gestores entrevistados revelaram compreender a inserção da criança aos seis anos no Ensino Fundamental e quais as orientaçóes teórico-metodológicas que estão embasando esse processo.

Alguns dizeres sinalizam que a formação docente e a organização de uma proposta pedagógica não fazem parte efetivamente do trabalho de alguns gestores, os quais deliberam ao professor as suas escolhas quanto, por exemplo, ao método a ser adotado, como neste dizer: "não tem um método próprio' o método que dá CERTO na sala de a::ula." Na profusão de sentidos que estão aí em latência, pode-se compreender que há confiança no trabalho do professor, que este tem formação e saber docente que lhe permitem orquestrar seu trabalho. Entretanto, levando em consideraçáo as pesquisas apresentadas aqui e os limites da implantaçáo de uma diretriz curricular na perspectiva de letramento, pode-se também depreender um discurso de liberdade e não responsabilidade. As implicaçóes decorrentes dessa ausência de decisóes e acordos teórico-metodológicos se fazem sentir a posteriori no desempenho dos alunos em eventos de letramento tanto escolares como em outras esferas.

Por outro lado, há gestores que se preocupam com a formação do professor e com a organização do trabalho pedagógico, levando em conta os saberes docentes, como revela o dizer de G4 quando se refere ao trabalho de acompanhamento e formação de professores:

"no prime::iro a::no foi foi MU::ITO interessante porque como eram duas esco::las né" cada esco::la tinha duas tu::rmas então qua::tro turmas' em uma esco::la era uma professo::ra SÓ pras duas tu::rmas e na outra esco::la era duas professo::ras' então nós tínhamos encontros MENSA::IS com essas professo::ras ã:: a::ntes de implantar a gente teve vá::rios enco::ntros de conve::rsa né" de:: tro::ca é:: [...] de dai NO segundo ano nós começamos a elaboração da PROPRO::STA pedagó::gica' a parti::r da experiê::ncia que essas professo::ras já tinham com a cria::nça' então não foi assi:m a:: nós construimos uma propro::sta pedagó::gica a::qui:: na secretaria de educaçâ:: o pra ser implantada da escola’ não' a propro::sta foi co::nstruida coo::rdenada pe::los técnicos DA secretaria COM a participaçã::o DOS professo::res que atendi::am essas crianças."

Municípios tão próximos, todos pertencentes à mesma associação, com possibilidade de diálogo e trocas, mas o que os registros coletados das 
entrevistas sinalizaram foram formas distintas de compreender o Ensino Fundamental de nove anos no que diz respeito à inserção da criança em práticas de linguagem. Há que se considerar as questóes culturais de cada município, mas não isolar cada fazer pedagógico como se não houvesse uma proposta mais ampla que orienta a implantação desse ensino e a inserção da criança de seis anos na escola.

Nesse percurso até aqui construído, compreendemos que um dos objetivos da mudança na idade escolar é antecipar, para muitas crianças, a participação em práticas de letramento escolar. Além disso, a criança tem mais tempo para compreender a organização do sistema alfabético e os usos sociais que essa compreensão acarretará. Os atores educacionais, ao pensarem na organizaçáo curricular dos anos iniciais, deveriam levar em conta as condiçóes de produção nas quais as diferentes comunidades de escrita se encontram. O currículo pode apresentar diretrizes sem isolar a construção das identidades, tão singulares que são.

Por fim, percebemos que a Lei (11.274) surgiu, mas ainda há muitos esclarecimentos para serem feitos e muitas dúvidas para serem dirimidas. Compreendemos, por meio dos dizeres, que ainda há um distanciamento entre o sistema que rege a educação (no caso da nossa pesquisa, sistema municipal) e a sala de aula. São sentidos provisórios, pois, como afirmou Bakhtin (2003, p. 410), "não existe a primeira nem a última palavra, e não há limites para o contexto dialógico", assim, outros sentidos emanarão do que até aqui foi analisado. Estamos todos na provisoriedade, desejosos por compreender mais.

\section{REFERÊNCIAS}

ABREU, M. M. de O. Ensino fundamental de nove anos no município de Uberlândia: implicaçóes no processo de alfabetização e letramento. 2009. 167 f. Dissertação (Mestrado em Educação) - Programa de pós-graduação em Educação, Universidade Federal de Uberlândia, Uberlândia, 2009. Disponível em: <http://www.bdtd.ufu.br//tde_busca/ arquivo.php?codArquivo=2717>. Acesso em: 20 mar. 2010.

ARROYO, M. G. Ofício de mestre: imagens e auto-imagens. 3. ed. Petrópolis: Vozes, 2001. 
BAKHTIN, M. Marxismo e filosofia da linguagem. São Paulo: Hucitec, 1992.

. Estética da criação verbal. 4. ed. São Paulo: Martins Fontes, 2003.

BAUER, Martin W; GASKELL, George. Pesquisa qualitativa com texto, imagem e som. Petrópolis, RJ: Vozes, 2002.

BRASIL. Secretaria de Educação Básica. Ensino fundamental de 9 anos: orientaçóes gerais. Brasília, 2004.

. Ensino fundamental de nove anos: orientaçóes para a inclusão da criança de seis anos de idade. 2. ed. Brasília, 2007.

. Presidência da República. Casa Civil. Lei Federal no 11.274, de 06 de fevereiro de 2006. Altera a redação dos arts. 29, 30, 32 e 87 da Lei $\mathrm{n}^{\circ}$ 9.394, de 20 de dezembro de 1996, que estabelece as diretrizes e bases da educação nacional, dispondo sobre a duração de 9 (nove) anos para o ensino fundamental, com matrícula obrigatória a partir dos 6 (seis) anos de idade. Brasília, 2006-2007. Disponível em: <http://www.planalto.gov. br/ccivil_03/_Ato2004-2006/2006/Lei/L11274.htm>. Acesso: 10 dez. 2010.

. Pró-Letramento: programa de formação continuada de professores de anos/séries iniciais do ensino fundamental: alfabetização e linguagem. Brasília, 2007a.

BUNZEN, C. Os significados do letramento escolar como uma prática sociocultural. In: VÓVIO, Cláudia et al. Letramentos: rupturas, deslocamentos e repercussóes de pesquisas em Linguística Aplicada. Campinas, SP: Mercado de Letras, 2010.

CAGLIARI, L. C. Alfabetizando sem o ba-bé-bi-bó-bu. São Paulo: Scipione, 1999.

CASSANY, D. Investigaciones y propuestas sobre literacidad actual: multiliteracidad, internet y criticidad. In: CONGRESO NACIONAL CÁTEDRA UNESCO PARA LA LECTURA Y LA ESCRITURA, 2005, Concepción, Chile. Anais eletrônicos... Concepción, Chile: UNESCO/Universidad de Concepción, 2005. Plenárias. Disponível em: <www2.udec.cl/catedraunesco/05CASSANY.pdf>. Acesso em: ago. 2006. 
COOK-GUMPERZ, J. A construção social da alfabetização. Porto Alegre: Artmed, 2002.

DIETRICH, M. D. Ensino fundamental de nove anos em Pelotas, RS: o projeto piloto da Secretaria Estadual de Educação para alfabetização de crianças com seis anos (Programa Circuito Campeão do Instituto Ayrton Senna). Itajaí: Univali, 2008. 17 p. CD-ROM.

DIONÍSIO, M. de L. Literacias em contexto de intervenção pedagógica: um exemplo sustentado nos novos estudos de literacia. Educação, Santa Maria, v. 32. n. 1, p. 97- 108, jan. 2007a.

. Educação e os estudos atuais sobre letramento. Perspectiva, Florianópolis, v. 25, n. 1, p. 209-224, jan./jul. 2007b. Entrevista concedida a Adriana Fischer e Nilcéa Lemos Pelandré.Disponível em: < http://www.perspectiva.ufsc.br/perspectiva_numeros_anteriores_2007_01.php>. Acesso em: 16 fev. 2009.

FARACO, Carlos Alberto. Linguagem e diálogo: as idéias do círculo de Bakhtin. 2. ed. Curitiba/PR: Criar Ediçōes, 2003.

FRADE, I. Alfabetização hoje: onde estão os métodos? Presença Pedagógica, Belo Horizonte, MG, v. 9, n. 50, p. 16-29, mar./abr. 2003.

FREITAS, Maria Teresa de Assunção. A perspectiva sócio-histórica: uma visão humana da construção do conhecimento. In: ; SOUSA, Solange Jobim, KRAMER, Sonia (Org.). Ciências humanas e pesquisa: leitura de Mikhail Bakhtin. 2. ed. São Paulo: Cortez, 2007. (Coleção Questões da Nossa Época; 107). 112p.

HEATH, S. B. What no bedtime story means: narrative skills at home and the school. Language and Society, United Kingdom, v. 11, p. 49-76, 1982.

HEINIG, O. L. de O. M.; STOLF, J. Os sentidos de alfabetização para os professores Alfabetizadores. In: CIRCULO DE ESTUDOS LINGUÍSTICOS DO SUL (CELSUL), 8., 2008, Porto Alegre. Anais eletrônicos... Porto Alegre: UFRGS, 2008. G.T. A linguagem na escola: contextos, desafios e perspectivas. Disponível em: <http://www.celsul.org. br/Encontros/08/sentidos_de_alfabetizacao.pdf>. Acesso em: mar. 2009. 
HOUAISS, A. Dicionário eletrônico Houaiss da lingua portuguesa. Rio de Janeiro: Objetiva, 2001. CD-ROM.

KLEIMAN, A. B. (Org.). Os significados do letramento: uma nova perspectiva sobre a prática social da escrita. Campinas, SP: Mercado de Letras, 1995.

. Letramento e formação do professor: quais as práticas e exigências no local de trabalho? In: KLEIMAN, A. B. (Org.). A formação do professor: perspectivas da lingüística aplicada. Campinas: Mercado de Letras, 2001. v. 1, p. 39-68.

. Os estudos de letramento e a formação do professor de língua materna. Linguagem em (Dis)curso, Tubarão, SC, v. 8, n. 3, p. 487-517, set./ dez. 2008.

LEAL, T.; ALBUQUERQUE, E. B.; MORAIS, A. G. Avaliação e aprendizagem na escola: a prática pedagógica como eixo de reflexão. In: BRASIL. Secretaria de Educação Básica. Ensino Fundamental de nove anos: orientaçóes para a inclusão da criança de seis anos de idade. 2. ed. Brasília, 2007.

MARCUSCHI, L. A. Análise da conversação. São Paulo: Ática, 1986.

MORAIS, A. G. Concepções e metodologias de alfabetização: por que é preciso ir além da discussão sobre velhos "métodos"?. In: BRASIL. Ministério da Educação. Secretaria de Educação Básica. Brasília, 2006. Disponível em: <http://portal.mec.gov.br/seb/arquivos/pdf/Ensfund/ alf_moarisconcpmetodalf.pdf $>$. Acesso em: 29 mar. 2010.

OSBORNE, A. B. Practice into theory into practice: culturally relevant pedagogy for students we have marginalized. Antropology and Education Quaterly, v. 27, n. 3, p. 285-314, sept. 1996.

ROJO, R. Letramento escolar: construção dos saberes ou de maneiras de impor o saber? In: CONFERÊNCIA DE PESQUISA SÓCIOCUlTURAL, 3., 2000, Campinas. Anais eletrônicos... Campinas: Unicamp, 2000. Disponível em: <http:/www.fae.unicamp.br/br2000/ credi.htm>. Acesso em: fev. 2010. 
ROJO, R. Alfabetização e letramento: sedimentação de práticas e (des) articulaçáo de objetos de ensino. Perspectiva, Florianópolis, v. 24, n. 2, p. 569-596, jul./dez. 2006.

. O letramento escolar e os textos de divulgação científica: a apropriação dos gêneros de discurso na escola. Linguagem em (Dis)curso, Tubarão, SC, v. 8, n. 3, p. 581-612, set./dez. 2008.

SANTA CATARINA. Proposta Curricular de Santa Catarina: estudos temáticos. Florianópolis: IOESC, 2005.

SCHNEUWLY, B.; DOLZ; J. Os gêneros escolares: das práticas de linguagem aos objetos de ensino. Revista Brasileira de Educação, São Paulo, n. 11, p. 5-16, maio/ago. 1999.

SOARES, M. Letramento: um tema em três gêneros. Belo Horizonte: Autêntica/CEALE, 1998.

. Letramento e alfabetização: as muitas facetas. In: REUNIÃO ANUAL DA ASSOCIAÇÃO NACIONAL DE PÓS-GRADUAÇÃO E PESQUISA EM EDUCAÇÃO (ANPED), 26., 2003, Poços de Caldas. Anais... Poços de Caldas: ANPEd, 2003. GT Alfabetização, Leitura e Escrita.

. Nada é mais gratificante do que alfabetizar: entrevista com Magda Soares. Letra A: o jornal do alfabetizador, Belo Horizonte, ano 1, n. 1, abr./maio 2005 .

STREET, B. Abordagens alternativas ao letramento e desenvolvimento. In: TELECONFERÊNCIA Unesco Brasil sobre 'Letramento e Diversidade’. Londres: Brian Street: King's College, 2003.

What's "new" in new literacy studies? critical approaches to literacy in theory and practice. Current Issues in Comparativ Education, NewYork, v. 5, n. 2, p. 1-14, 2003 b.

TARDIF, M. Saberes docentes e formação profissional. 2. ed. Petrópolis, RJ: Vozes, 2002. 


\section{Initial reading instruction and literacy on school scenery: comprehensions of educational managers}

\begin{abstract}
:
"The understanding of literacy in new educational administrations" is a research that was held with education managers responsible for the initial years of elementary school from six cities of Santa Catarina. The aim of this paper is to understand the conception of language that supports the implementation of the nine years long elementary school. The instrument of data collection used was the narrative interview. From the statements, it appears that literacy and initial reading instruction are understood dichotomously, which involves the pedagogical acting and, within it, the role of the teacher and the curriculum organization. There is also a concern about the teaching of reading and writing in the first year.
\end{abstract}

Keywords: Basic education of nine years. Literacy. Educational administrators.

\section{Alfabetización y literacidad en el escenario escolar: comprensión de los gestores educacionales}

\section{Resumen}

El trabajo de investigación "La comprensión de la literacidad en las nuevas administraciones educacionales" se realizó con directores educacionales responsables por los primeros años de la enseñanza básica de seis municipios del Estado de Santa Catarina, Brasil. El objetivo de este artículo es comprender la concepción de lenguaje que fundamenta la implantación de de nueve años obligatorios en la Enseñanza Básica. La entrevista narrativa fue el instrumento de colecta de datos. De los enunciados registrados se desprende que la literacidad y la alfabetización son comprendidos dicotómicamente, lo que interfiere en el ejercicio pedagógico, en el papel del profesor y en la organización curricular. También hay una inquietud en relación a la enseñanza de lectura y de escritura en el primer año de enseñanza básica.

Palabras clave: Enseńanza Básica de nueve ańos. Literacidad. Directores de Educación.

\section{Otilia Lizete de Oliveira Martins Heinig}

Endereço: Programa de Pós-graduação em Educação e no curso de Letras da FURB. Rua Edgar Von Buettner, 350. Bairro Bateias. Brusque, SC.

CEP: $88355-350$

Telefone: (47) 33500504 (resid) / (47) 33210533 (FURB)

Email: otilia.heinig@gmail.com

Recebido em: 01/7/2010

Aprovado em: 5/10/2010 